\title{
Go Long or Short in Pyramids? \\ News from the Egyptian Stock Market
}

Andreas Billmeier and Isabella Massa 



\title{
IMF Working Paper
}

\author{
Middle East and Central Asia Department
}

\section{Go Long or Short in Pyramids? News from the Egyptian Stock Market}

\author{
Prepared by Andreas Billmeier and Isabella Massa ${ }^{1}$
}

Authorized for distribution by Klaus Enders

July 2007

\begin{abstract}
This Working Paper should not be reported as representing the views of the IMF.

The views expressed in this Working Paper are those of the author(s) and do not necessarily represent those of the IMF or IMF policy. Working Papers describe research in progress by the author(s) and are published to elicit comments and to further debate.

Similar to other emerging economies, the Egyptian stock market has recently experienced a remarkable run-up but also a major downturn. This paper analyzes the stock market from two angles. First, it compares the performance of the major stock price index with its underlying fundamentals. Second, it explores the relationship between the Egyptian and other stock markets. The paper finds that (i) there is some evidence against a stable relationship between the Egyptian index and its fundamental value; and (ii) short-term correlations and long-term cointegrating relations provide conflicting signals on the value of Egyptian stocks as a means of diversification.
\end{abstract}

JEL Classification Numbers: G11, G15, C32, C33, F30

Keywords: Egypt, stock market, CASE, integration, cointegration, market capitalization Authors' E-Mail Addresses: abillmeier@imf.org, massa.isabella@unive.it

\footnotetext{
${ }^{1}$ Isabella Massa is a Ph.D. student at Ca' Foscari University in Venice, Italy. This paper was largely written while she was an intern in the IMF's Middle East and Central Asia Department. The authors would like to thank Klaus Enders, Nadeem Ilahi, Nicole Laframboise, Mohammed Omran (Cairo and Alexandria Stock Exchanges), and seminar participants at the IMF for helpful comments; Anna Maripuu for help with the data; Judith Rey for careful editing; and Mohammed Omran for providing data.
} 


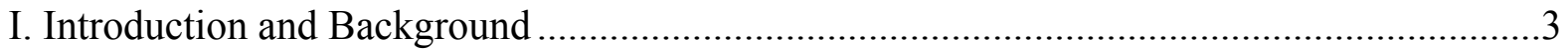

II. How Strong is the Link Between Egyptian Share Prices and Fundamentals? ......................5

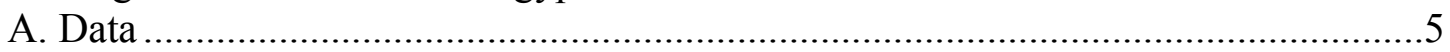

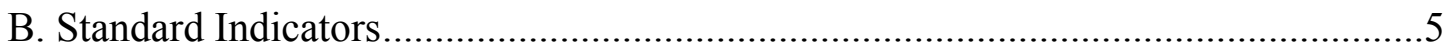

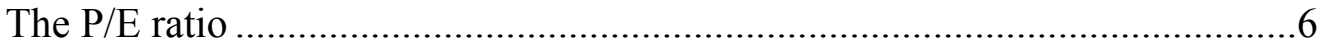

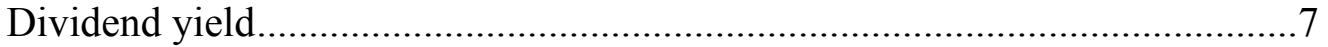

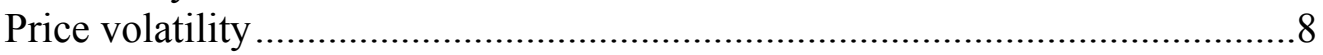

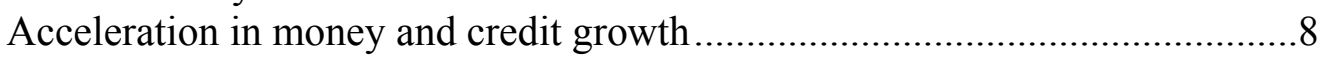

C. Variance Bounds Test .................................................................................

Background .....................................................................................

Sample construction and methodology ........................................................10

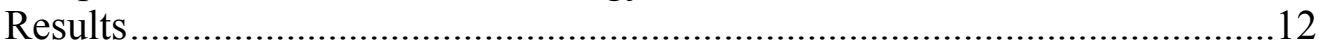

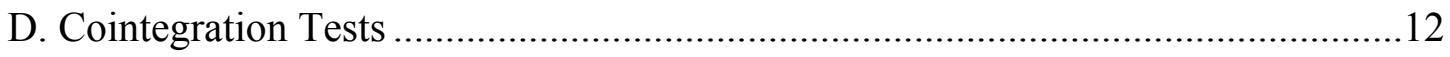

The statistical model .....................................................................................13

Interpreting the cointegration evidence ……………….................................... 14

III. Does the Egyptian Stock Market Lead or Follow? And Who(m)?..................................15

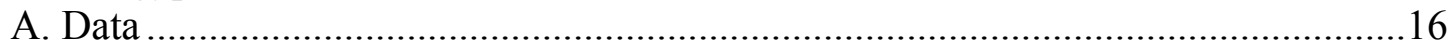

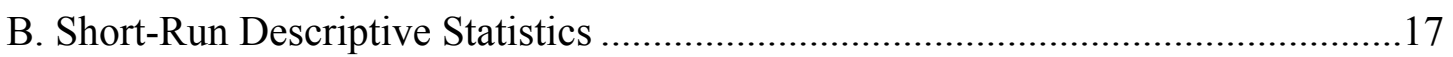

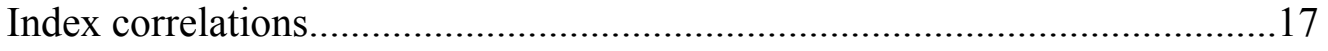

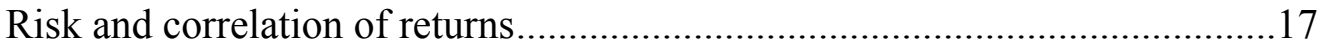

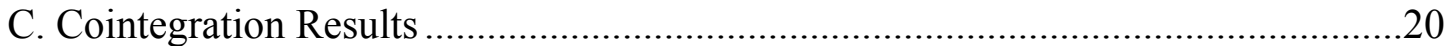

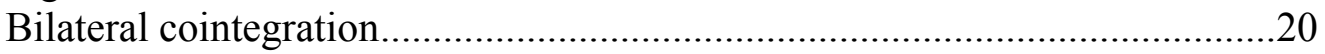

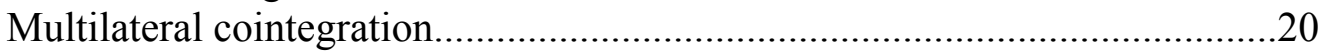

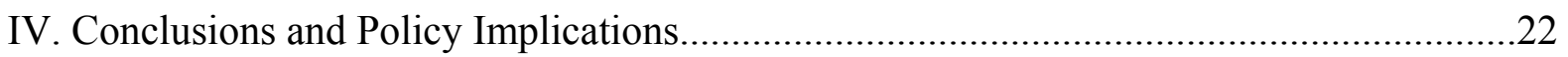

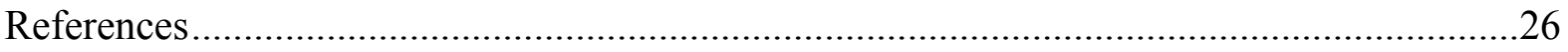

Tables

1. Egypt: Summary Statistics of CASE 30 and Dividend Indices, 2001-06 …......................10

2. Egypt: Cointegration Properties Between Stock Price and Dividend Index, 2001-06........15

3. Egypt: Correlations with Other Stock Market Indices, 1998-2006 ...................................18

4. Egypt: Weekly Stock Index Returns, 1998-2006 ............................................................19

5. Egypt: Cointegration with Other Stock Markets, 1998-2006 ………...............................21

Figures

1. Egypt: CASE 30 Composition by Economic Sector, 2002-06...........................................

2. Egypt: Nominal, Real, and Fundamental Indices, 2001-06 ..............................................11

3. Selected Middle East and Emerging Market Economies:

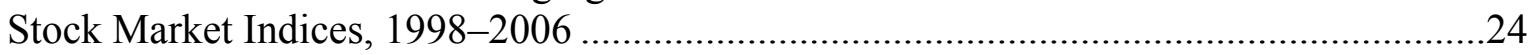

4. Selected Economies: Stock Market Indices, 1998-2006 ………….................................25 


\section{INTRODUCTION AND BACKGROUND}

Over the past few years, stock market indices around the world have experienced a period of strong growth compared to the long-run average. Developed markets have recovered rather swiftly from the technology bubble a few years ago, and emerging markets have seen startling amounts of liquidity channeled toward their stock exchanges, driving up stock prices. Selected markets have experienced major corrections, partly related to economic crises. Some of these corrections were temporary, others more pronounced.

In the Middle East and Central Asia, several economies have, partly boosted by oil revenues, established or enhanced their equity markets recently. In other countries, where stock markets have existed for a long time, (investor) interest in them has grown drastically in the recent past as they have seen major swings.

Egypt's stock market is a prime example of a long-established market that has received a lot of investor attention over the last few years, with substantial consequences for stock market capitalization and stock price indices. Founded in 1883 and 1903, the Alexandria and Cairo stock exchanges are among the oldest stock markets in the region. After strong activity in the 1940s, interest subsided somewhat until about 10 years ago when the two stock exchanges were joined under the present institutional setup, the Cairo and Alexandria Stock Exchanges (CASE). The new management embarked on a revitalization and reform agenda, including, since 2002, a delisting of about 500 stock companies that were not traded. About half of the remaining 600 companies, however, still display very low to negligible turnover. Stock market capitalization, in turn, increased from 31 percent to 80 percent of GDP over the same period. The major index, CASE 30, combines the 30 most liquid companies listed on the exchange with a minimum of 15 percent free float.

After several years of weak performance, equity markets across the Middle East region boomed in 2003-05, experienced strong corrections in early 2006, and struggled ever since (as reflected by the Shuaa Index, see text figure). ${ }^{2}$ The Egyptian stock market, however, recovered rather swiftly from the set back. The CASE figures among the best-performing stock markets worldwide over the last few years. At its highest point during the last nine years, in February 2006, the Egyptian stock market index was, on a U.S. dollar basis,

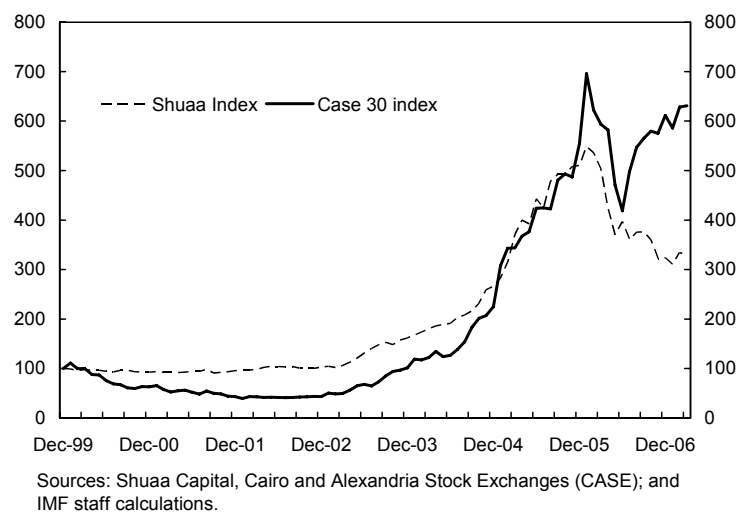

${ }^{2}$ The Shuaa index includes the countries organized in the Cooperation Council for the Arab States of the Gulf (GCC), Egypt, Jordan, Lebanon, Morocco, Tunisia, and West Bank and Gaza. In addition to Egypt, several other countries contained in the index saw a speedy recovery after last year's stock index correction, especially Morocco and Tunisia. 
almost 12 times as high as at the low point in March 2003 - in less than three years! ${ }^{3}$

While these returns are certainly attractive, the Egyptian stock market has also garnered attention as an uncorrelated risk; that is, as a means to diversify risk in international portfolios. This is due to the fact that, to some extent, the Egyptian economy is somewhat of a "hybrid:" it has certain features of classic emerging markets in Latin America or Asia, (for example international market access); in terms of per-capita income, however, it is lagging these markets but also other emerging economies in the Middle East with major stock markets, including due to Egypt's smaller natural resource endowment.

Notwithstanding these stylized facts, the local stock market has received little attention in the finance and economics literature on Egypt; this paper attempts to partly fill this gap. We explore whether to go long or short in pyramids from two angles - from a performance and from a portfolio diversification perspective. First, since extraordinary increases in stock prices are historically often associated with the existence of speculative bubbles, we investigate whether there was or is evidence that equity prices may have been driven by factors other than market fundamentals over the past few years. In this context, we look at several stock valuation measures, and apply two statistical techniques to test for speculative bubbles: a variance bounds test, and a test for long-run cointegration between the CASE 30 index and its fundamentals. We find that there is some limited evidence of overvaluation in the Egyptian stock market in the last three years but that an improved economic environment could bode well for continued performance of the Egyptian stock market.

Second, we consider the Egyptian stock market from a portfolio diversification perspective and analyze whether, in the short or long run, Egyptian stocks move with other equity markets. In light of anecdotal evidence, we also explore whether these relationships have changed over time, using September 11, 2001 as a structural break point. We find that correlations of the Egyptian CASE 30 index with most other markets (of both levels and changes) have risen dramatically between the two periods, whereas the correlation of returns has only increased with some Arab markets. This is not mirrored, however, by long-run developments as evidence for bilateral cointegration is weak. There is, hence, still scope for portfolio diversification in the longer run. In a multivariate framework, Egypt appears cointegrated with—but not influenced by—other Arab stock markets.

From here on, the paper is structured as follows. Section II investigates the nexus between stock market prices and underlying fundamentals in the CASE. In Section III, we turn to a cross-country perspective, and investigate whether the Egyptian stock market is integrated with other stock markets in the Middle East and elsewhere and to what extent this relationship has changed over the past few years. Section IV offers some conclusions and policy implications.

\footnotetext{
${ }^{3}$ To some extent, this is mirrored by the fact that models relating stock market capitalization to macroeconomic variables have difficulties explaining the developments in recent years, hinting at possible misalignments between stock price indices and underlying fundamentals; see Billmeier and Massa (2007).
} 


\section{How Strong is the Link Between Egyptian Share Prices And Fundamentals?}

In local currency, the CASE 30 index rose by more than 750 percent during the last 9 years notwithstanding the severe correction in early $2006 .{ }^{4}$ Such extraordinary increases in stock prices are, however, sometimes associated with the existence of speculative bubbles. Notorious examples include the dot-com bubble in 2000/01, but also the Nikkei bubble in 1989 and the 1998 bubble in the Omani stock market.

To shed light on whether stock prices are in line with fundamentals or rather over-valued, we discuss in this section a number of standard descriptive indicators, along the lines of SaadiSedik and Petri (2006). Moreover, the literature on asset price bubbles provides at least three approaches to empirically assess the presence of speculative bubbles - tests for bubble premia, excess volatility tests, and non-stationarity and cointegration tests. We will explore the last two strategies to infer on the relation between Egyptian stock prices and underlying fundamentals, which are commonly derived from historical data using the dividend discount method.

Applicability of these concepts depends on stationarity properties of the times series considered. While the excess volatility test implicitly assumes that the series are (trend-)stationary, the cointegration approach is only meaningful in a non-stationary context.

\section{A. Data}

The data used in this section are the monthly closing prices of the CASE 30 price index, as well as the corresponding dividend yields and price-to-earnings ratios. ${ }^{5}$ Data related to broad money, the Egyptian wholesale price index, and domestic credit growth stem from the Fund's International Financial Statistics database. The period analyzed covers June 2001 to December 2006, constrained by the availability of dividend yield data.

\section{B. Standard Indicators}

Speculative bubbles arise when asset prices increase at a rate that is greater than the one that can be explained by the underlying fundamentals (Kindleberger, 1992). To assess whether in the Egyptian stock market share prices have moved in line with their fundamentals, we provide descriptive evidence on two conventional stock valuation measures - the price-toearnings ratio (P/E) and the dividend yield (DY). ${ }^{6}$ Moreover, we also consider price volatility and spurts in liquidity as potential indicators of price developments that are not in line with fundamentals.

\footnotetext{
${ }^{4}$ The correction in 2006 occurred simultaneously with, but was much more limited than those in other markets in the region, including Saudi Arabia and Jordan.

${ }^{5}$ We would like to thank Mohamed Omran from the CASE for providing these data as well as data on the composition of the price index over time.

${ }^{6}$ Another commonly used stock valuation measure is the price-to-book ratio. We were, however, not able to obtain a time series for this indicator for the CASE 30 index.
} 


\section{The $\mathrm{P} / \mathrm{E}$ ratio}

The $\mathrm{P} / \mathrm{E}$ ratio measures how expensive a company's stock is relative to its most recent earnings. A high $\mathrm{P} / \mathrm{E}$ ratio indicates investor willingness to pay a higher price for the security as they expect higher future earnings. After being flat for a few years, the $\mathrm{P} / \mathrm{E}$ ratio of the CASE 30 index started to increase in 2003. It reached a value of about 24 at end2006, which is almost twice its historical average - a common benchmark (see text figure). While such a trending $\mathrm{P} / \mathrm{E}$ ratio could

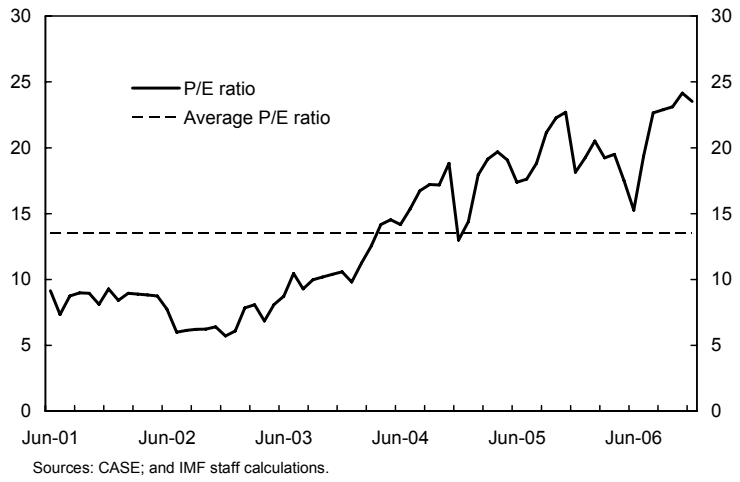
be considered an indicator for growing overvaluation, the evidence is somewhat less strong when the $\mathrm{P} / \mathrm{E}$ levels are compared to other economies, including developed economies. ${ }^{7}$ Moreover, the $\mathrm{P} / \mathrm{E}$ ratio remains substantially below the ones achieved in other regional markets before they experienced a correction in 2006 and does not offer, at this stage, a clear indication for overvaluation. ${ }^{8}$

Furthermore, the rising $\mathrm{P} / \mathrm{E}$ ratio could be due to sampling bias - changes in the composition of the CASE 30 index - rather than to an over-valuation of share prices. Indeed, a "fair" P/E ratio is often industry-specific. At a firm level, for example, IT companies have P/E ratios that are often higher than those belonging to the textile sector as IT and "new technology" companies tend to be younger and earlier in their product cycle. Accordingly, market valuation takes into account expected future earnings that are higher in dynamic growth industries. For this reason, we checked the composition by sector of the CASE 30 index over the period from January 2002 to January 2007. Visual inspection of Figure 1 indicates that the share of companies in the IT and media and telecommunication sector has, in fact, tripled from 10 percent in the first half of 2002 to 30 percent in the second half of 2006 . However, this increase occurred mainly in 2006, implying that the growing presence of dynamic companies in the CASE 30 index is not enough to explain the increase of the $\mathrm{P} / \mathrm{E}$ ratio between 2003 and 2005 .

\footnotetext{
${ }^{7} \mathrm{P} / \mathrm{E}$ ratios for major economies have been between 33.6 (Canada) and 18.4 (United Kingdom) just before the 1998 correction, and between 14.7 (France) and 24.0 (United States) immediately after; see OECD (1998). Dynamic emerging markets often trade at a premium.

${ }^{8}$ Saadi-Sedik and Petri (2006) show that the P/E ratio on the Amman Stock Exchange reached a value of about 45 in 2005. P/E ratio in Saudi Arabia before the 2006 correction reached a value of 80.
} 
Figure 1. Egypt: CASE 30 Composition By Economic Sector, 2002-06 (In percent of total index; unweighted)

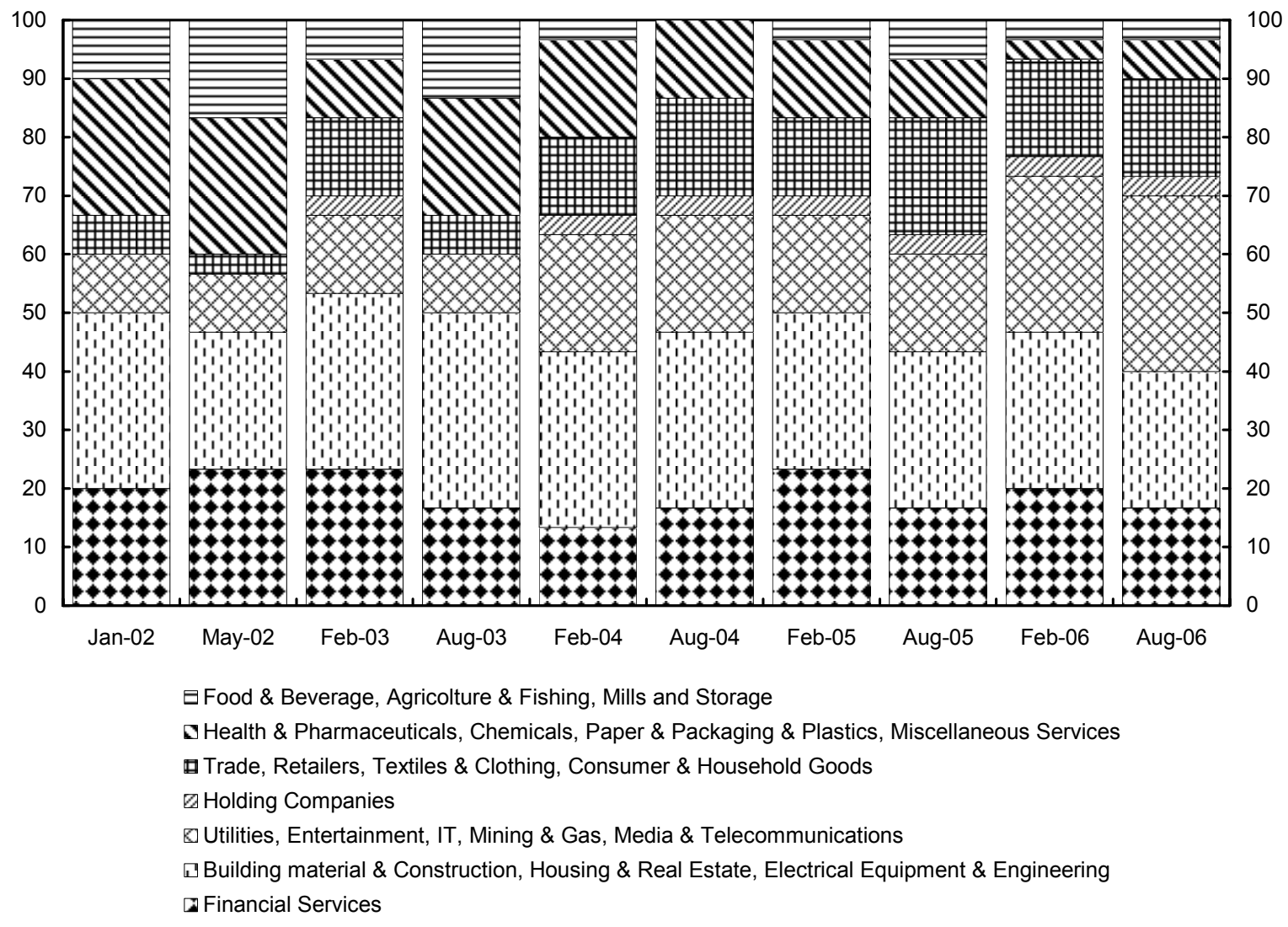

Sources: CASE; and IMF staff calculations.

\section{Dividend yield}

Further evidence is provided by the dividend yield - the ratio between the amount of dividends paid per share over a certain period and the current share price. As expected in light of the take-off of actual share prices, the dividend yield of the CASE 30 index has dramatically decreased in the past few years (see text figure). Since end-2001, the dividend yield fell continuously until the February 2006 stock market correction set in. After reaching a low at 2.4 percent in January 2006,

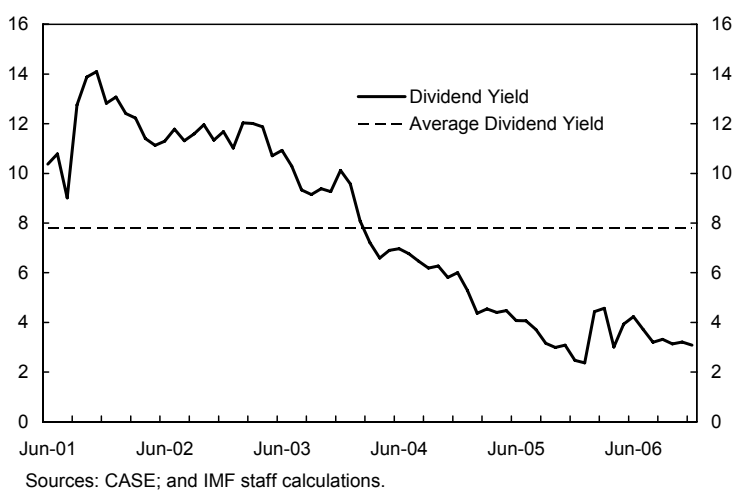
the index remains at about one third of the historical average of 7.8 percent. After a short rebound during the stock market correction in early 2006, the dividend yield remained broadly flat notwithstanding the resuming strong growth of equity prices, indicating that, starting in the second half of 2006, earnings grew in line with the index. 


\section{Price volatility}

The presence of a bubble in stock markets is also usually associated with a substantial increase in price volatility. ${ }^{9}$ Indeed, strong price volatility is often considered by investors a signal of an imminent bursting of a bubble, leading to a flight into quality. ${ }^{10}$ As the stock price index displays characteristics of a non-stationary time series, we cannot draw any conclusions from the standard deviation of the index. Instead, we investigate the standard deviation of the daily returns of the CASE 30 index for the period January 2002 to December

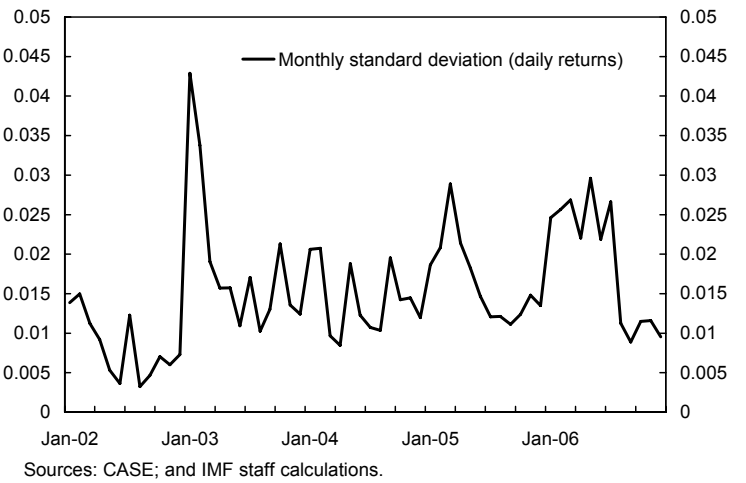

\section{Acceleration in money and credit growth}

A rapid expansion of broad money and credit can lead to a larger amount of savings channeled through stock markets and thus to a level of stock prices that is no longer in line with its fundamentals. ${ }^{12}$ Therefore, we check for the existence of a relationship between the CASE 30 price index movements and the growth of broad money and credit to the private sector (see text figure). There appears to be no relationship between the CASE 30 and broad money. Some of the additional 2006 (see text figure). After a sudden increase in price volatility at the beginning of 2003 when stock prices took off, price volatility abated again somewhat. ${ }^{11}$ The correction in February 2006 was preceded by a doubling of the standard deviation. However, an even more pronounced increase occurred in early 2005, when the market correction was still a year away. Higher volatility of daily returns, therefore, do not provide conclusive evidence for the existence of a speculative bubble.

private sector credit in 2005-06 could have been channeled to the stock market. The growth rates involved are, however, small compared to credit booms seen in other countries at a similar stage of development and there appears to be little relation between the stock market boom and these alternative measures of liquidity. In other words, most of the stock market acceleration appears to be driven by foreign (as opposed to domestic) liquidity.

\footnotetext{
${ }^{9}$ See Topol (1991).

${ }^{10}$ The so-called safe-haven effect, see, e.g., OECD (1998).

${ }^{11}$ This appears to be chronologically related to the floating of the Egyptian pound on January 29, 2003.

${ }^{12}$ See, among others, Allen and Gale (2003).
} 


\section{Variance Bounds Test}

\section{Background}

Shiller (1981) introduced variance bounds tests for stock prices to examine higher-order statistical properties of stock markets by comparing the variance of actual stock prices with the variance of underlying fundamental prices. In an efficient market, the variance of actual prices should be smaller than the variance of fundamental prices since actual prices $\left(P_{t}\right)$ are the optimal forecast of their underlying fundamentals $\left(P_{t}^{*}\right)$. According to the present value model and assuming investors' perfect foresight, fundamental prices $\left(P_{t}^{*}\right)$ are given as the present value of actual future discounted dividends:

$$
P_{t}^{*}=\sum_{i=1}^{\infty}\left(\frac{1}{1+r}\right)^{i} D_{t+i}
$$

where $r$ is the one-period constant required rate of return and $D_{t+i}$ are dividends $i$-periods into the future. Since actual prices are given by $P_{t}=E_{t}\left(P_{t}^{*}\right)$, the fundamentals can be rewritten as $P_{t}^{*}=P_{t}+u_{t}$, where $u_{t}$ is the forecast error. Focusing on the second-order moment yields:

$$
\operatorname{var}\left(P_{t}^{*}\right)=\operatorname{var}\left(P_{t}\right)+\operatorname{var}\left(u_{t}\right)+2 \cdot \operatorname{cov}\left(P_{t}, u_{t}\right)
$$

but since $P_{t}$ is an optimal forecast of $P_{t}{ }_{t}$, the forecast error must be uncorrelated with the forecast; that is, the covariance between $P_{t}$ and $u_{t}$ is zero. It follows that:

$$
\operatorname{var}\left(P_{t}^{*}\right) \geq \operatorname{var}\left(P_{t}\right)
$$

Equation (3) places an upper bound on the variance of actual stock prices and forms the basis for excess volatility tests. In his contribution, Shiller (1981) shows that the inequality is not borne out by the data, and concludes that the present value model and the efficient market hypothesis are flawed. ${ }^{13}$ Other authors - including Tirole (1985) and Blanchard and Watson (1982) - suggest that the violation of the variance bound may be related to the existence of a speculative bubble, in the presence of which the variance of actual stock prices could be greater than the variance of fundamental prices. From a statistical point of view, this test assumes of course that the actual price and dividend series are, at least over the sample period, (trend-)stationary as comparing variances for non-stationary series is futile.

\footnotetext{
${ }^{13}$ Shiller (1981) uses real annual data for dividends and prices from the S\&P Composite Index for the years 1871-1979, and from the Dow Jones Industrial Average for the years 1928-1979.
} 


\section{Sample construction and methodology}

To test for excess volatility in the Egyptian stock market over the sample period, we use the monthly closing prices and the monthly dividend yields of the CASE 30 index. In constructing the series, we broadly follow the methodology in Brooks and Katsaris (2003). Both indices are normalized (June $2001=100)$ and transformed into real variables using the monthly Egyptian WPI, which is considered more reliable than the CPI, especially before 2004. Summary statistics about the CASE 30 index and the constructed dividend index are reported in Table 1.

Table 1. Egypt: Summary Statistics for CASE 30 and Dividend Indices, 2001-06

\begin{tabular}{lcccccccc}
\hline & \multicolumn{2}{c}{ CASE 30 Index } & & \multicolumn{2}{c}{ Dividend } & Index & & \multicolumn{2}{c}{ Gordon Fundamentals Index } \\
\cline { 2 - 3 } & Nominal & Real & & Nominal & Real & & Nominal & Real \\
\hline Mean & 439.7 & 3.0 & & 203.6 & 1.5 & & 267.8 & 1.9 \\
Standard deviation & 404.6 & 2.5 & & 106.5 & 0.6 & & 143.5 & 0.8 \\
Peak value & 1336.6 & 8.9 & & 510.9 & 3.4 & & 704.2 & 4.6 \\
Peak date & Jan-06 & Jan-06 & & Feb-06 & Feb-06 & Apr-07 & Mar-07 \\
\hline
\end{tabular}

Sources: CASE; and IMF staff calculations.

The two top panels of Figure 2 contain plots of the normalized CASE 30 price and dividend indices in both nominal and real terms. Visual inspection indicates that, until mid-2004, both indices remain fairly aligned. Starting in the second quarter of 2004, however, the two indices diverge due to a much steeper increase of the price index.

To apply the variance bounds test, we constructed fundamental prices using the Gordon growth model (Gordon, 1962), which is perceived in the literature as a simple, clear, and more realistic framework than the methodology used by Shiller (1981) for discounting dividends. Assuming that real discount and expected real dividend growth rates are constant over time, fundamental prices are defined as:

$P_{t}^{*}=\frac{(1+g)}{(i-g)} D_{t-1}$

where $P_{t}{ }^{*}$ is the fundamental price at time $t ; g$ is the expected future growth rate of dividends; $i$ is the real discount rate; and $D_{t-1}$ is the dividend of the previous period. Even though the dividend growth and the discount rates are assumed to remain constant over time, fundamental prices can be constructed without assuming investors' perfect foresight regarding the dividends. ${ }^{14}$

\footnotetext{
${ }^{14}$ The Gordon growth model appears a good choice, though, to compute the fundamentals of the CASE 30 index given that the index includes, over much of the observation period, a high percentage of slow-growing companies like utilities, financial services, and real estate companies for which $g<i$ is more likely to hold (see Figure 1).
} 
Figure 2. Egypt: Nominal, Real, and Fundamental Indices, 2001-06 (June $2001=100)$
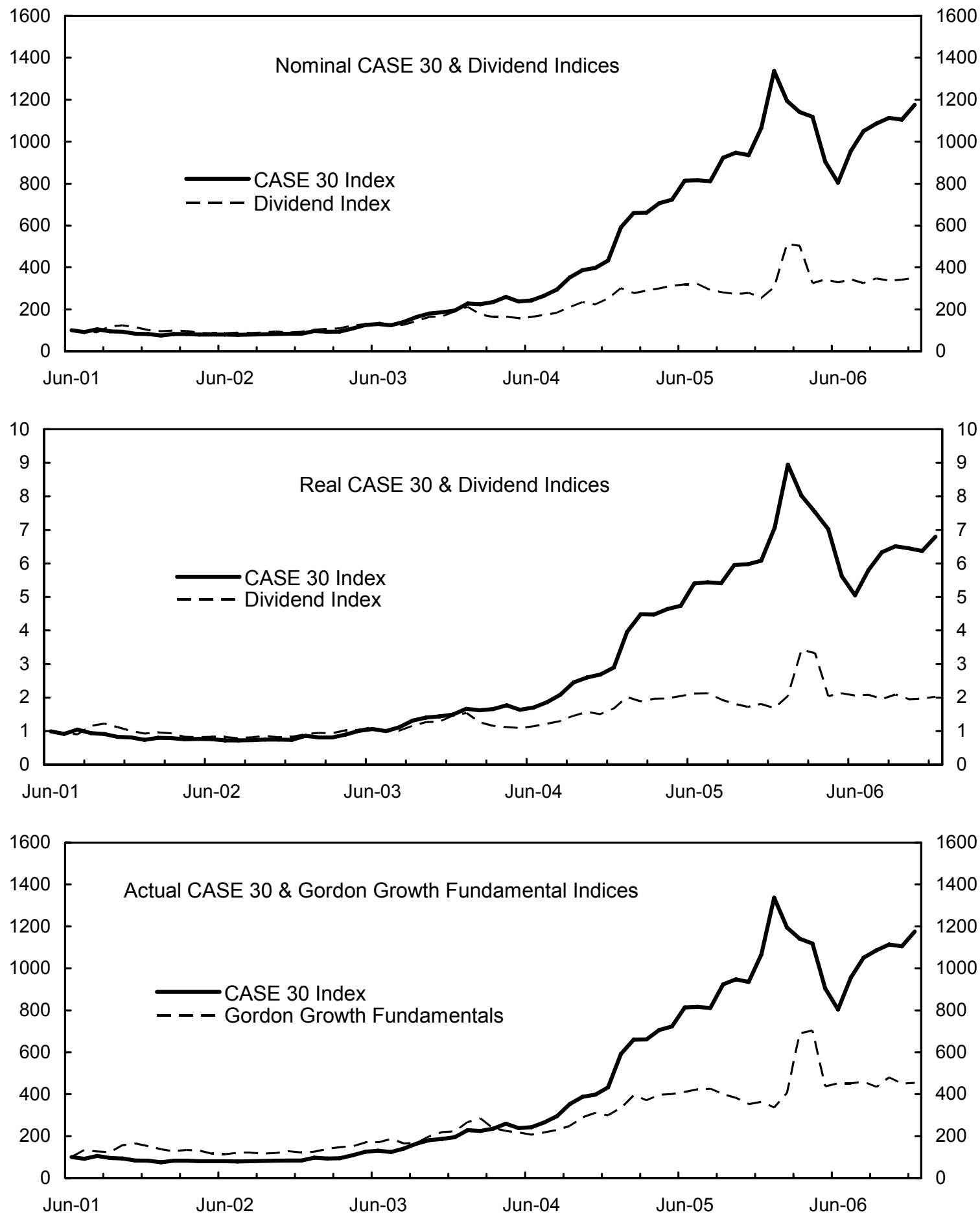

Sources: CASE; and IMF staff calculations. 
The discount rate used is the average CASE 30 real return and the dividend growth rate is the average growth of real cash dividends, both for the whole period. The monthly observations of fundamental values were transformed back into nominal variables using the WPI and normalized in order to obtain the monthly series of the fundamental values index. Some descriptive statistics of the constructed fundamental prices are provided in Table 1 (above).

\section{Results}

The bottom panel of Figure 2 displays the trend of the fundamental values index from the Gordon growth model and the CASE 30 price index. An initial period of slight undervaluation (from June 2001 to mid-2004) is followed by a period of increasing distance between the index and its fundamentals which reaches its peak in January 2006. The end of the second quarter of 2004 was a period of political and economic changes in Egypt, as the new government under Prime Minister Nazif took office in June 2004, and the new economic team moved quickly to implement a number of reforms and announced plans to restructure the financial sector and privatize more state enterprises. Such a wave of reforms may have provided the basis for forming very optimistic expectations on the Egyptian economy in general and corporate performance in particular, driving the actual price of the CASE 30 index far above its fundamental value.

To examine the variance bounds test assumption empirically, the variance of the actual CASE 30 price index and the variance of the fundamental values index are computed for the sample period and compared using an $F$-test, where the null hypothesis is that the variance of actual prices is not larger than the variance of the fundamental values as per equation (3). This hypothesis is rejected at the 1-percent level, with a test statistic of 7.95, thus providing some evidence for excess volatility in the Egyptian stock market.

The variance bounds test is, however, very sensitive to the specification of fundamental values and the Gordon growth model itself is, in turn, weakened by the assumptions of constant discount and dividend growth rates. Moreover, the model assumption that the stock price index and dividends are (trend-)stationary appears questionable. ${ }^{15}$ To corroborate the results, we conduct a short cointegration analysis, geared at nonstationary data.

\section{Cointegration Tests}

The relationship between stock prices and dividends is described by the following asset pricing formula:

$$
P_{t}=\sum_{i=1}^{\infty} \frac{E_{t}\left(D_{t+i}\right)}{(1+r)^{i}}+b_{t}
$$

\footnotetext{
${ }^{15}$ Marsh and Merton (1986), and Kleidon (1986), among others, argue that Shiller's variance bounds test is unreliable since it is based on the inappropriate assumption of stationarity for the dividend process. However, Shiller's methodology is still widely used in the literature since tests that adjust for dividend nonstationarity tend not to yield more consistent results.
} 
where $P_{t}$ is the actual (index) price, $D_{t}$ are the dividends and $r$ is a fixed discount rate. The first complex term on the right side gives the fundamental values, while $b_{t}$ is the stochastic bubble term which satisfies the condition $b_{t}=E_{t}\left(b_{t+1}\right) /(1+r)$ - there are no negative bubbles. Hence, if both the stock market index and dividends - representing the "true" firm valueare best described from a statistical perspective as non-stationary variables, cointegration theory could help identify a long-term stationary relationship between the two variables, indicating the absence of a stock market bubble. ${ }^{16}$ The opposite outcome, no long-run relationship between prices and true value of the firm, indicates a non-stationary behavior of $b_{t}$ and could be interpreted as a speculative bubble. In the present context, however, these models carry a set of specification issues. Moreover, due to small sample sensitivity, applying the cointegration approach to Egypt is severely hampered by the limited amount and span of observations available. Finally, the absence of cointegration property between the two series does not necessarily indicate the presence of a bubble as the lack of cointegration could be caused by other factors. ${ }^{17}$

\section{The statistical model}

To analyze the data, we employ a general cointegrated $\operatorname{VAR}(\mathrm{k})$ model, written in error correction form:

$$
\Delta X_{t}=\Pi X_{t-1}+\sum_{i=1}^{k-1} \Gamma_{i} \Delta X_{t-i}+\mu_{0}+\mu_{1} t+\varepsilon_{t}, \quad t=1, \ldots, T
$$

Where $X_{t}$ is a p-dimensional autoregressive process, $k$ is the lag length, $\varepsilon_{t}$ is an i.i.d. error with mean zero and variance $\Omega, \Pi=\sum_{i=1}^{k} \Pi_{i}-\mathrm{I}, \Gamma_{i}=-\sum_{j=i+1}^{k} \Pi_{j}$. In the present context, $X_{t}$ is two-dimensional, and composed of the stock market $\left(P_{t}\right)$ and dividend $\left(D_{t}\right)$ indices. Under the $\mathrm{I}(1)$ hypothesis that $\operatorname{rank}(\Pi)=r<p$, the decomposition $\Pi=\alpha \beta^{\prime}$ holds, where $\alpha, \beta$ are $p \times r$ matrices of rank $r$ and $\alpha_{\perp}^{\prime} \Gamma \beta_{\perp}$ has full rank $(p-r)$, where $\alpha_{\perp}, \beta_{\perp}$ are the orthogonal complements of $\alpha, \beta$, and where $\Gamma=\sum_{i=1}^{k-1} \Gamma_{i}$. The trend is restricted to the cointegrating space; that is $\alpha_{\perp}^{\prime} \mu_{1}=0$, since quadratic trends are not observed in the data.

\footnotetext{
${ }^{16}$ Both variables have been tested for a unit root using the conventional tools (Augmented Dickey Fuller and Phillips-Perron tests). Only for one model (Augmented Dickey-Fuller, including a trend), the null of a unit root in the level of the dividend index can be rejected at the 5-percent level. There were no indications of unit roots in first differences. The results are subject to the usual short-sample criticisms and are available from the authors.

${ }^{17}$ See Diba and Grossman (1988a, 1988b) and Johansen (1991). Brooks and Katsaris (2003) offer evidence that price developments on the London Stock exchange in the second half of the 1990s have not been consistent with economic fundamentals.
} 
The moving average representation of this I(1) process defines the data-generating process for $X_{t}$ as a function of the errors $\varepsilon_{t}$, the initial values $\mathrm{A}_{0}$, and the variables in $F_{t}$ and is given by:

$$
X_{t}=C\left(\sum_{i=1}^{t}\left(\varepsilon_{i}+\Phi F_{i}\right)+\mu_{0} t\right)+C^{*}(L)\left(\varepsilon_{t}+\mu_{0}+\mu_{1} t+\Phi F_{t}\right)+A_{0},
$$

where $C=\beta_{\perp}\left(\alpha_{\perp}^{\prime} \Gamma \beta_{\perp}\right)^{-1} \alpha_{\perp}^{\prime} . C^{*}(L)$ is a finite polynomial in the lag operator $L$, and $\mathrm{A}_{0}$ is a function of the initial values. The cointegrating vectors are estimated by reduced rank regression of $\Delta X_{t}$ on $\left(X_{t-1}, t\right)$, corrected for lagged differences and the constant, see Johansen (1996), Theorem 6.2.

\section{Interpreting the cointegration evidence}

To assess whether the cointegration property holds, we have estimated models for (i) the whole period for which stock market closing prices and dividend yield data are available (May 2001-December 2006); and (ii) two subperiods, before and after the Nazif government took office in June 2004.

The empirical evidence is summarized in Table 2. For the whole observation period (Panel A), there is limited evidence of one cointegrating relationship. Models with a lower amount of lags (one or two lags) - for which the evidence is stronger-display autocorrelation in the residuals. Evidence of cointegration between the stock price index and dividends is weaker in models that capture the data better (three and more lags). The CASE 30 index appears to be weakly exogenous, indicating that dividend yields are mainly driven by the denominator (stock prices) as opposed to the opposite situation in which the stock price index would be driven by (expectations on) the dividends. In the first subperiod (until May 2004, Panel B), there is evidence for one cointegrating relationship, indicating that the stock price index has been driven by the same common trend as the dividend index. The picture is somewhat more murky for the second period as the evidence for cointegration again depends on the amount of lags in the model (Panel C). For the most parsimonious model shown in the table (two lags), the data indicates one cointegrating relationship, but residual tests show significant autocorrelation (at the 7 percent level). In models fully consistent with the data and the autocorrelation assumptions on the VAR residuals (three and four lags), the cointegration property becomes weaker. More importantly, though, it appears that the dividend index is trend-stationary for most models except the one with two lags, casting doubt on the assumption that a cointegrating model is an appropriate description of the data. ${ }^{18}$

\footnotetext{
${ }^{18}$ As a sensitivity test, we experimented with a different sample break (December 2003). The results are broadly similar in that (i) there appears to be evidence for one cointegrating relationship during the first period; (ii) the evidence for a cointegrating relationship in the second period depends strongly on the amount of lags chosen for the empirical model; and (iii) the CASE 30 index is weakly exogenous.
} 
To summarize, the evidence stemming from the cointegration approach corroborates to some extent the evidence from the excess volatility test. It appears, however, that the volatility evidence for a bubble in the latter half of the observation period is somewhat stronger than the results from the cointegration exercise, where there is less evidence that the stock market and dividend indices diverged in a fundamental sense. Due to the short time span covered by the data (especially for the subperiods), however, the cointegration results should not be seen as conclusive evidence since cointegration is a long-run phenomenon. Moreover, the fact that the dividend series is only borderline non-stationary implies that both tests are somewhat limited in their effectiveness. In fact, we are trying to establish a relationship between a mainly stationary (dividend index) and a non-stationary (CASE 30) series-whereas the tools used are geared to deal with either stationary or non-stationary data.

Table 2. Egypt: Cointegration Properties Between Stock Price and Dividend Index, 2001-06

\begin{tabular}{|c|c|c|c|c|c|c|}
\hline Model 1/ & Lags & Stationarity & $\begin{array}{c}\text { Weak } \\
\text { exogeneity }\end{array}$ & $\begin{array}{l}\text { Largest } \\
\text { eigenvalue }\end{array}$ & $\begin{array}{l}\text { Trace statistic } \\
\text { Ho: } r=0 \text { vs. } r \leq 1\end{array}$ & $\begin{array}{l}95 \text { percent } \\
\text { critical value }\end{array}$ \\
\hline \multicolumn{7}{|c|}{ Panel A. Full Sample (2001M05-2006M12) } \\
\hline $\begin{array}{c}\text { Unrestricted } \\
\text { constant }\end{array}$ & 3 & none & $\begin{array}{c}\text { CASE index } \\
(0.098)\end{array}$ & 0.212 & $\begin{array}{l}15.621 \\
(0.046)\end{array}$ & 15.408 \\
\hline \multicolumn{7}{|c|}{ Panel B. Period I (2001M05-2004M5) } \\
\hline $\begin{array}{l}\text { Restricted } \\
\text { trend }\end{array}$ & 1 & none & $\begin{array}{c}\text { CASE index } \\
(0.043)\end{array}$ & 0.443 & $\begin{array}{l}27.082 \\
(0.033)\end{array}$ & 25.731 \\
\hline \multicolumn{7}{|c|}{$\underline{\text { Panel C. Period II (2004M06-2006M12) }}$} \\
\hline \multirow{3}{*}{$\begin{array}{r}\text { Restricted } \\
\text { constant }\end{array}$} & 2 & none & $\begin{array}{c}\text { CASE index } \\
(0.088)\end{array}$ & 0.495 & $\begin{array}{l}26.454 \\
(0.005)\end{array}$ & 20.164 \\
\hline & 3 & $\begin{array}{c}\text { Dividend index } \\
\quad(0.328)\end{array}$ & $\begin{array}{c}\text { Dividend index } \\
\quad(0.283)\end{array}$ & 0.485 & $\begin{array}{l}23.792 \\
(0.014)\end{array}$ & 20.164 \\
\hline & 4 & $\begin{array}{c}\text { Dividend index } \\
(0.537)\end{array}$ & $\begin{array}{c}\text { Dividend index } \\
\quad(0.313)\end{array}$ & 0.354 & $\begin{array}{l}17.219 \\
(0.126)\end{array}$ & 20.164 \\
\hline
\end{tabular}

Sources: CASE; and IMF staff calculations.

Note: The table displays the most parsimonious models that do not cause rejection by common residual tests, including autocorrelation, $\mathrm{ARCH}$, and normality. Strictly speaking, the asymptotic properties of the cointegration method only depends on the i.i.d. assumption for errors, not on normality (Johansen 1996). The detailed statistical results regarding the model selection have been omitted to contain space but are available from the authors upon request. P-values are given in parenthesis.

1/ Model describes the type of deterministic components included in the model, see Johansen (1996), p. 80.

\section{Does the Egyptian Stock MARKet Lead OR Follow? AND Who(M)?}

Investigating the links to other stock markets can provide additional insights in the international role of the Egyptian stock market. Reportedly, the sell-off between February and June 2006 - when the CASE 30 index lost about 33 percent - was triggered by investors from the Gulf region that faced margin calls at home and had to liquidate some of the foreign equity positions. One of the motivations for their initial investment in Egypt - other than dynamic share price development — could have included the expectation to hedge risk by 
diversifying into a market with a low $\beta$. On the other hand, there is anecdotal evidence that a large share of Egyptian sovereign liabilities (treasury bills, etc.) are held in Europe, as opposed to the Gulf or the U.S. market. Finally, Italy is Egypt's largest European export market, and one could expect that trade (flow) links are conducive to forging stock market co-movements, either directly through possible cross-border equity holdings, or indirectly due to business linkages.

There is some evidence of cointegration between Arab stock markets. In a study similar to ours, Saadi-Sedik and Petri (2006) — henceforth SSP — found that Jordan's stock exchange index is cointegrated with many other Arab markets, implying little long-run regional risk diversification. They do not find, however, any long-run relationship with other emerging or advanced countries, pointing to risk-diversification potential from outside the region.

While we take a similar approach to SSP (cointegration), we are interested in a slightly different set of questions: (i) in the long run, is the Egyptian stock price index moving together with other indices; (ii) if yes, is the Egyptian index leading or following; and (iii) have the cointegration properties changed over time? To answer the last question, we need to split the nine-year sample. We refrain from statistical testing for structural breaks and assume that market conditions may have changed in the wake of September 11, 2001. This is consistent with anecdotal evidence of, for example, restrictions on cross-border investment due to tightened Anti-Money Laundering/Combating the Financing of Terrorism (AML/CFT) regulations, and increasing home bias of investors of Middle Eastern origin.

\section{A. Data}

The data used in this section are sourced from DataStream and consist of weekly stock indices over the nine-year period January 6, 1998 through December 26, 2006 for a total of 469 observations. Given the imposed break date, the first subsample has therefore 192 observations, the second 277 observations. For the reasons discussed in SSP, we use Tuesday indices. Where available, we use the Standard\&Poor's (S\&P's) IFC index measures in U.S. dollars and local currency. ${ }^{19}$ For some countries not included in the S\&P database, we use local currency indices (Lebanon, Kuwait) ${ }^{20}$ The results for the bivariate cointegration are based on the indices denominated in U.S. dollars; the multivariate regional cointegration results are based on local-currency indices as more regional indices are available in local currency. ${ }^{21}$ Stock market indices have been found to be non-stationary, and our set of indices is no exception. ${ }^{22}$

\footnotetext{
${ }^{19}$ This also includes the Egyptian S\&P index on a U.S. dollar basis. The Egyptian local-currency index corresponds to the CASE 30 index.

${ }^{20}$ The main results hold when using local indices (e.g. DAX, CAC40, FTSE100, MIBTEL), as the S\&P index closely tracks these indices. The results have been omitted due to space constraints.

${ }^{21}$ See the discussion in SSP on the trade-off between using U.S. dollar versus local currency indices.

${ }^{22}$ Results have been omitted but are available from the authors. See SSP for results on most indices used in this paper.
} 


\section{B. Short-Run Descriptive Statistics}

\section{Index correlations}

Over the full sample, the Egyptian stock market is highly correlated with other stock markets in the region and elsewhere (Table 3). This holds especially true on a U.S. dollar basis, where average correlations are quite similar across country groups. On a local-currency basis, correlations are higher with Arab and Emerging Market (EM) economies, compared to developed economies. Investigating the whole sample period, however, masks an important fact: for literally all country-currency pairings, the correlation (in levels) is substantially higher in Period II, after September 11, 2001. For some countries, correlations in the first part of the sample are, in fact, negative. This suggests that the factors driving short-term stock market developments have changed and are more similar in the second part of the sample. We observe also that in local-currency terms, the level correlation in Period II is very high with Arab and emerging markets, and a bit less so with markets in advanced economies.

The rapid stock market index growth in many markets in Period II, however, may drive some of these stunning correlation results. Therefore, we turn to (stationary) stock market returns.

\section{Risk and correlation of returns}

Table 4 confirms that the two periods are also very different from a return perspective, with the second period yielding substantially higher mean returns for all indices. The average weekly return for the Egyptian index is 0.16 percent on a U.S. dollar basis, and 0.27 percent on an Egyptian pound basis. This is among the highest returns for the full sample. In period II, however, the return from investing in the Egyptian stock market - at $0.65 / 0.75$ percent per week - exceeds by far that of any other stock market in the sample (except the S\&P Europe index which includes some fast-growing Euro-area stock markets). ${ }^{23}$ Egypt is, however, also one of the most risky investments as measured by the standard deviation of the return. The Sharpe ratio, a measure of the risk-adjusted return, is in fact not significantly higher than that of other countries in the region.

Similarly, return correlations change between the two subperiods, especially within the region (last section of Table 3). In fact, Egyptian returns are much more correlated in the second period with Arab and other emerging markets, while there is no significant change in return correlation for the developed economies.

\footnotetext{
${ }^{23}$ SSP found that the Saudi stock market yielded the highest average return, at 0.53 percent per week. These figures, however, predate the major correction in Middle East stock markets in 2006, which was more pronounced in Saudi Arabia.
} 


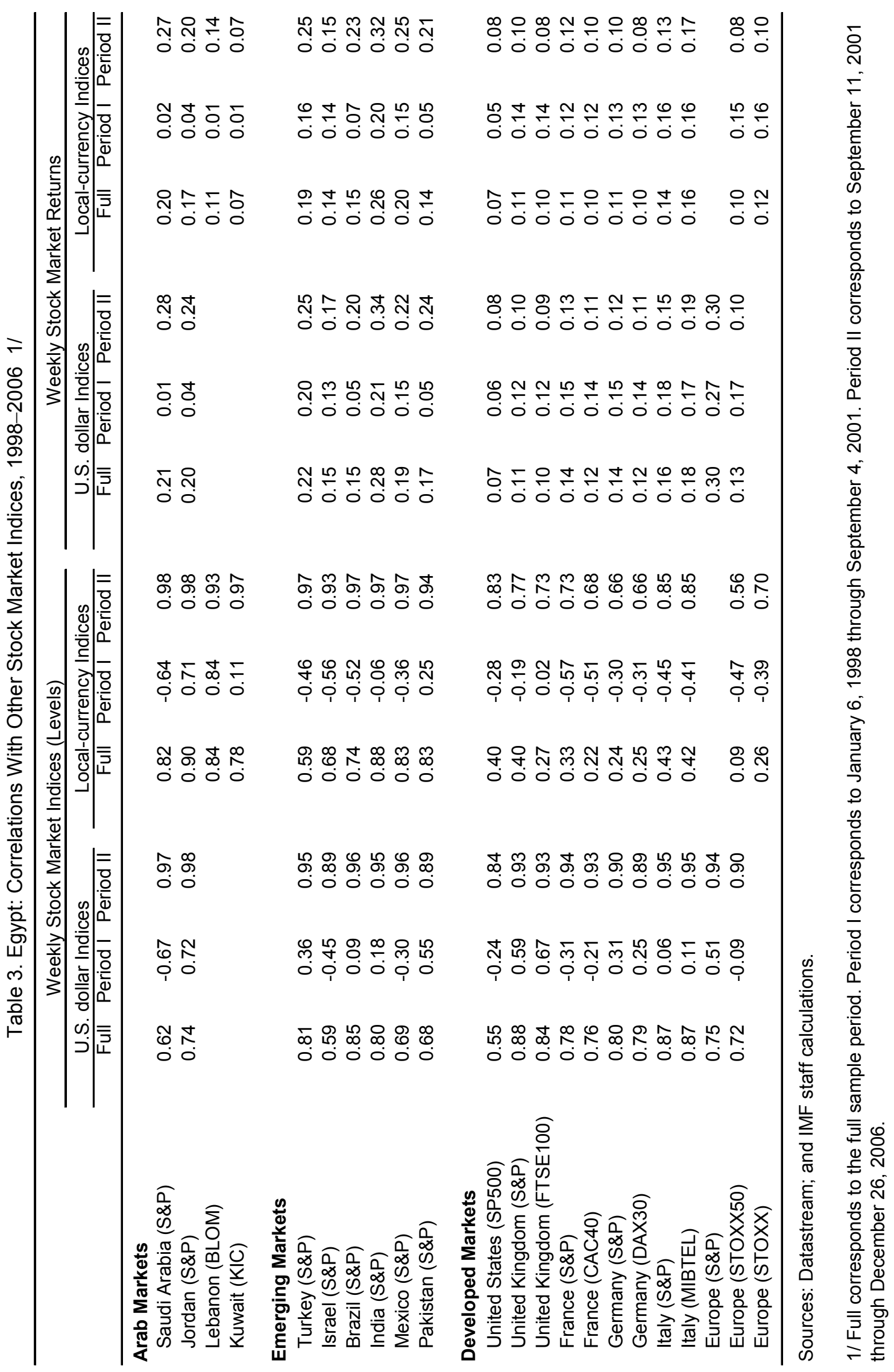




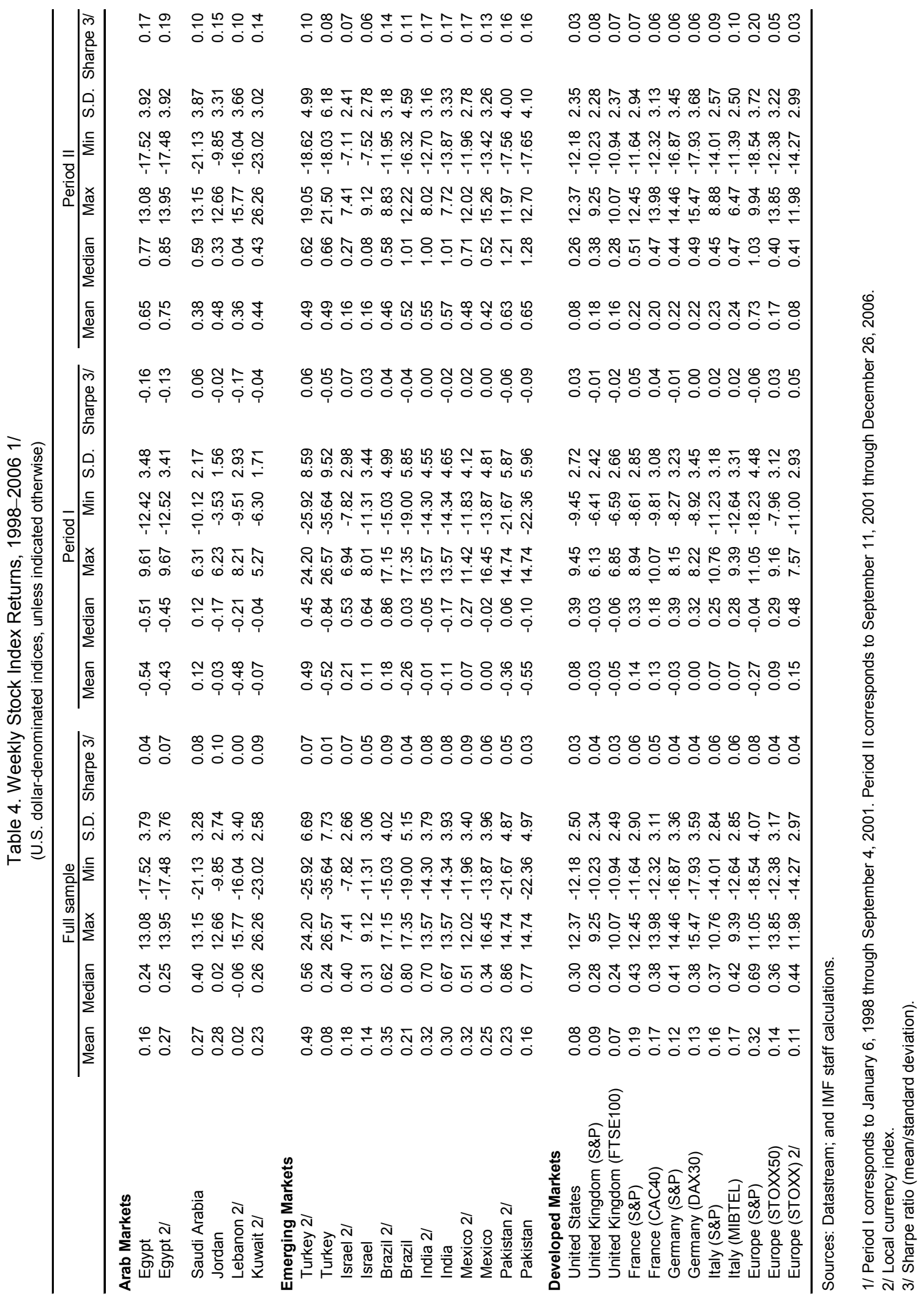




\section{Cointegration Results}

The drastic change of short-run correlations between period I and period II triggers the question whether longer-run behavior has also changed, especially between Egypt and other Arab markets. We focus, in turn, on bivariate relationships between Egypt and selected other markets and multilateral relationships between those countries in the region that are contained in our sample.

\section{Bilateral cointegration}

The bivariate cointegration tests indicate that there is only very weak support of the cointegration hypothesis. Only in the case of Italy, the data provide solid evidence for a longrun relationship between the two stock markets, mainly driven by the first period (Panel A in Table 5 and Figures 3 and 4). ${ }^{24}$ Mexico and Pakistan appear to be borderline significant, but only for the whole sample. Notably, the Egyptian stock market does not appear to be cointegrated with either Saudi Arabia or Jordan. In other words, evidence from the short-run correlations pointing to an increasing degree of interrelation (in levels and differences, see above) is not mirrored in the long-run analysis.

This result stands in contrast with one of the findings of SSP, who documented a set of bilateral cointegrating relationships between Jordan and other Arab markets, including Egypt. It appears that one additional year of data (and a few observations at the beginning) compared to SSP has wiped out the evidence in favor of a long-run relationship between the two countries' stock market indices. ${ }^{25}$ Visual inspection of Figure 3 points to Egypt's quick recovery from the 2006 downturn as a possible explanation for this finding.

\section{Multilateral cointegration}

To investigate the regional diversification potential, we have estimated a VAR with the five Middle East indices in local currency (Egypt, Jordan, Kuwait, Lebanon, Saudi Arabia), again for the whole sample and for period I and II separately (Table 5, Panel B). Consistent with $\mathrm{SSP}$, there is some evidence for regional cointegration over the whole sample. Splitting the sample, however, leads to the conclusion that the regional markets were not cointegrated in the first period, and only weakly so after September 2001. This is consistent with the diversification theme-regional investors selected Egypt as a destination since in the past both the short-run (weekly) correlations and the long-run relationships pointed to a means to reduce risk in an international portfolio. The assumption of a low market correlation at a weekly frequency proved elusive, however, after September 2001, a period that includes the regional stock market boom and downturn. From a long-run perspective, however, Egypt continues to be somewhat decoupled from the movements of other regional stock markets.

\footnotetext{
${ }^{24}$ Although the test statistics are significant, the largest eigenvalue is rather low, implying a partial correlation of just above 20 percent between the linear combination of $X_{t-1}$ and the stationary process $\Delta X_{t}$.

${ }^{25}$ In fact, we are able to reproduce their results by restricting the sample appropriately.
} 
Table 5. Egypt: Cointegration with Other Stock Markets, 1998-2006 1/

\begin{tabular}{|c|c|c|c|c|c|c|c|c|c|}
\hline & \multicolumn{3}{|c|}{ Full Sample } & \multicolumn{3}{|c|}{ Period I } & \multicolumn{3}{|c|}{ Period II } \\
\hline & Eigenvalue & Trace & Corr. Trace & Eigenvalue & Trace & Corr. Trace & Eigenvalue & Trace & Corr. Trace \\
\hline \multicolumn{10}{|c|}{ A. Bilateral Cointegration (U.S. dollar indices) $2 /$} \\
\hline \multicolumn{10}{|l|}{ Arab Markets } \\
\hline Saudi Arabia & 0.019 & 0.773 & 0.788 & 0.051 & 0.628 & 0.676 & 0.041 & 0.752 & 0.777 \\
\hline Jordan & 0.028 & 0.498 & 0.520 & 0.053 & 0.721 & 0.763 & 0.047 & 0.657 & 0.687 \\
\hline \multicolumn{10}{|l|}{ Emerging Markets } \\
\hline Turkey & 0.025 & 0.269 & 0.288 & 0.083 & 0.240 & 0.285 & 0.074 & 0.043 & 0.055 \\
\hline Israel & 0.025 & 0.282 & 0.303 & 0.065 & 0.361 & 0.413 & 0.028 & 0.738 & 0.767 \\
\hline Brazil & 0.035 & 0.149 & 0.164 & 0.047 & 0.672 & 0.716 & 0.025 & 0.730 & 0.758 \\
\hline India & 0.019 & 0.422 & 0.444 & 0.045 & 0.843 & 0.870 & 0.027 & 0.701 & 0.730 \\
\hline Mexico & 0.044 & 0.073 & 0.082 & 0.061 & 0.457 & 0.508 & 0.027 & 0.761 & 0.786 \\
\hline Pakistan & 0.031 & 0.069 & 0.078 & 0.081 & 0.262 & 0.311 & 0.054 & 0.143 & 0.166 \\
\hline \multicolumn{10}{|l|}{ Developed Markets } \\
\hline Germany & 0.033 & 0.083 & 0.093 & 0.102 & 0.076 & 0.099 & 0.026 & 0.822 & 0.843 \\
\hline Italy & 0.042 & 0.013 & 0.016 & 0.102 & 0.061 & 0.083 & 0.033 & 0.507 & 0.543 \\
\hline France & 0.033 & 0.048 & 0.055 & 0.055 & 0.208 & 0.244 & 0.031 & 0.406 & 0.436 \\
\hline United Kindom & 0.030 & 0.114 & 0.126 & 0.072 & 0.347 & 0.394 & 0.028 & 0.840 & 0.858 \\
\hline United States & 0.028 & 0.099 & 0.110 & 0.059 & 0.559 & 0.603 & 0.027 & 0.766 & 0.790 \\
\hline \multicolumn{10}{|c|}{ B. Multilateral Cointegration (Local currency indices) 3 / } \\
\hline \multicolumn{10}{|l|}{ Cointegrating vectors } \\
\hline$(r=0)$ & 0.093 & 0.004 & 0.016 & 0.153 & 0.163 & 0.398 & 0.140 & 0.007 & 0.058 \\
\hline At most $1 \quad(r \leq 1)$ & 0.049 & 0.192 & 0.644 & 0.095 & 0.435 & 0.818 & 0.100 & 0.150 & 0.400 \\
\hline At most $2 \quad(r \leq 2)$ & 0.029 & 0.341 & 0.674 & 0.085 & 0.457 & 0.991 & 0.054 & 0.564 & 0.896 \\
\hline At most $3 \quad(r \leq 3)$ & 0.021 & 0.263 & 0.769 & 0.055 & 0.646 & 0.979 & 0.030 & 0.662 & 0.855 \\
\hline At most 4 & 0.020 & 0.159 & 0.507 & 0.018 & 0.808 & 0.980 & 0.021 & 0.507 & 0.565 \\
\hline
\end{tabular}

Sources: Datastream; and IMF staff calculations.

1/ Period I corresponds to January 6, 1998 through September 4, 2001. Period II corresponds to September 11, 2001 through December 26, 2006.

$2 /$ In Section A, the table shows the maximum eigenvalue, and p-values for the trace test statistic and the Barlett-corrected trace statistic for the null hypothesis of no cointegration $(r=0)$ versus the alternative of at most one cointegrating relationship ( $r \leq 1)$;see Johansen (2002, 1996). No model indicated $r=2$, which would imply that the matrix $\Pi$ in equation (6) is of full rank and cointegration analysis, therefore, an inappropriate tool. Almost all bivariate models are estimated using four lags (some models include more lags to account for remaining residual autocorrelation).

3/ In Section B, the model shows the same test statistics as Section A for the null of $r=s$ versus the alternative $r>s$. The model for the first subperiod is estimated using four lags, the other two models use six lags. All models include a trend restricted to the cointegrating space.

Restricting the cointegration rank to 1 reveals that:

- In the full sample model, the exclusion of the Saudi and Jordanian indices from the cointegrating relationship cannot be rejected with a p-value of 0.374 (0.493 after Bartlett correction, see Johansen, 2000) under a $\chi^{2}$ distribution with two degrees of freedom. Moreover, excluding in addition the Kuwaiti index and imposing weak exogeneity for the Egyptian index cannot be rejected at the 10-percent level $\left(\chi^{2}(4)\right)$. In other words, the Lebanese stock index adjusts, in the long run, to the Egyptian index corrected for a trend.

- In the model for the second period, the Kuwaiti index can again be excluded from the cointegrating relationship. Moreover, several zero restrictions on the adjustment 
coefficients can also not be rejected (jointly) with a p-value of 0.601 under a $\chi^{2}$ distribution with 5 degrees of freedom. Only the Jordanian index is adjusting to a disequilibrium in the long-run relationship between the other four indices-including the Egyptian index.

\section{Conclusions ANd Policy Implications}

The Egyptian stock market has developed very rapidly over the last few years. Similar to other stock markets in the region, a period of extraordinary growth has been followed by a correction and renewed optimism, nurtured by a rather quick recovery compared to most of its peers. Nonetheless, it has attracted only a very limited amount of research in the finance and economics literature on Egypt. This paper intended to partly fill this gap by asking whether investing in the Egyptian stock market could be attractive from two angles: a performance perspective - comparing actual stock prices with underlying fundamentals - and a portfolio diversification perspective - investigating the links with other equity markets.

The evidence of the link between the Egyptian stock index and its underlying fundamentals is mixed. While some indicators can be interpreted as pointing to a slowly growing overvaluation in the second half of the sample (P/E ratio and variance bounds test), other indicators do not provide conclusive evidence in this respect (return volatility, dividend yields). The cointegration test-which offers weak evidence in favor of a bubble - suffers from the short span of the series (between 30 and 35 months per subperiod) and the fact that the dividend yield is borderline stationary. We interpret these results to imply that a small overvaluation of the Egyptian stock market, especially in early 2006, cannot be rejected - but that the evidence is much less clear-cut than in other countries in the region and elsewhere at certain points in the past.

Conflicting signals regarding the Egyptian stock market also emanate from the evidence presented on portfolio diversification. Short-term correlations clearly indicate an increasing degree of interrelatedness between the Egyptian and many other stock indices. The difference between correlations before and correlations after September 11, 2001 is surprising. While we cannot rule out the possibility of structural breaks in investor behavior, it appears that to a large extent the short-run co-movement between indices is driven by the worldwide liquidity surplus, to which high oil prices have contributed in a sizeable way. Evidence of long-term bilateral cointegrating relationships, however, is weak. This suggests that the Egyptian stock market is still somewhat decoupled from most other stock markets, and that it offers, in the long run, some scope for portfolio diversification.

From a policy perspective, it appears that the implementation a strong economic reform agenda since 2004 has led to a drastic improvement of public expectations about Egypt's economic future-including strong future corporate earnings and a higher growth trajectory. The development of the Egyptian stock market can be seen as one manifestation of these improved expectations. To confirm these expectations, the government should continue to improve the business environment and enhance investment incentives-including through further privatizations - to allow corporations to make and distribute profits that would be in line with rapid stock market growth. From a macroeconomic perspective, further stock 
market development could be bolstered by increased private savings channeled through stock market vehicles, for example investment funds.

Moreover, the Egyptian authorities need further policies that ensure that the broad public benefits from this financial boom, and at the same time prevent eventual drastic equity market corrections. First, in light of anecdotal evidence that the price fluctuations in early 2006 were partly due to large-scale divesting from less sophisticated investors in stocks with limited liquidity, the Egyptian authorities should strive to enhance the amount of trading, and continue to improve market transparency and further downsizing the CASE by delisting stocks that are rarely (or not at all) traded. Second, implementing an appropriately supervised secondary (small cap) market at the CASE would enhance access to financing for small and medium enterprises that are not able to cope with the listing requirements for the prime market and could also lead to better market segmentation. Third, the development of securitized and derivative products would lead to the development of new risk management systems and strategies at the corporate level for companies that do not have access to international finance. Fourth, enhancing the quality of accounting standards as well as enforcing the frequent disclosure of investor information by listed companies will contribute to educating the investor base. Fifth, strong data systems are the backbone of a timely dissemination of financial information, and the government could strengthen the CASE, possibly in the context of its efforts to provide information and communications technology parks. Finally, from a regulatory perspective, the reinforcement of the supervisory framework currently being implemented by the Central Bank of Egypt (CBE) will lead to a more resilient banking system, more likely to jumpstart lending operations and take investment positions as it moves away from simply holding high-yield government debt. In this context, continued cooperation and information exchange between the CASE, the Capital Markets Authority, and the CBE should lead to a strong framework for banks' balance sheet analysis, risk-based prudential limits on banks' portfolio composition, as well as a sophisticated stress testing methodology.

Further research could, among many other topics, compare stock markets across emerging economies in the Middle East, focusing on institutional issues. 
Figure 3. Selected Middle East and Emerging Market Economies: Stock Market Indices, 1998-2006 $($ Weekly Indices, January $1998=100)$
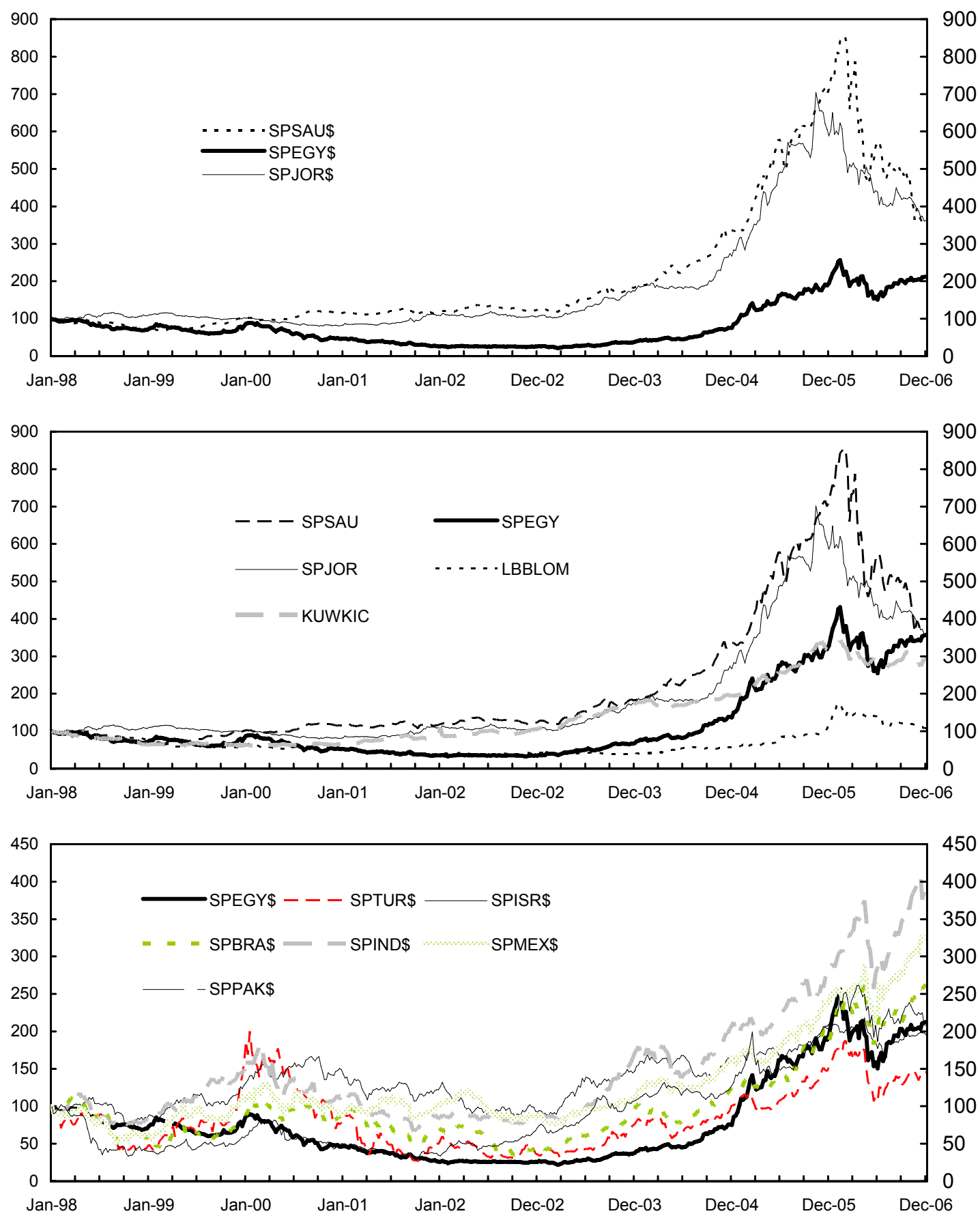

Sources: Datastream; and IMF staff calculations.

Note: SP at the beginning of the index descriptor denotes an index sourced from the Standard\&Poor's database. The \$-sign at the end denotes an index denominated in U.S. dollar. "SAU" stands for the Saudi Arabian, "EGY" for the Egyptian, "JOR" for the Jordanian, "LBBLOM" for the Lebanese, "KUWKIC" for the Kuwaiti, "TUR" for the Turkish, "ISR" for the Israeli, "BRA" for the Brazilian, "IND" for the Indian, "MEX" for the Mexican, and "PAK" for the Pakistani index. 
Figure 4. Selected Economies: Stock Market Indices, 1998-2006

(Weekly Indices, January $1998=100$ )
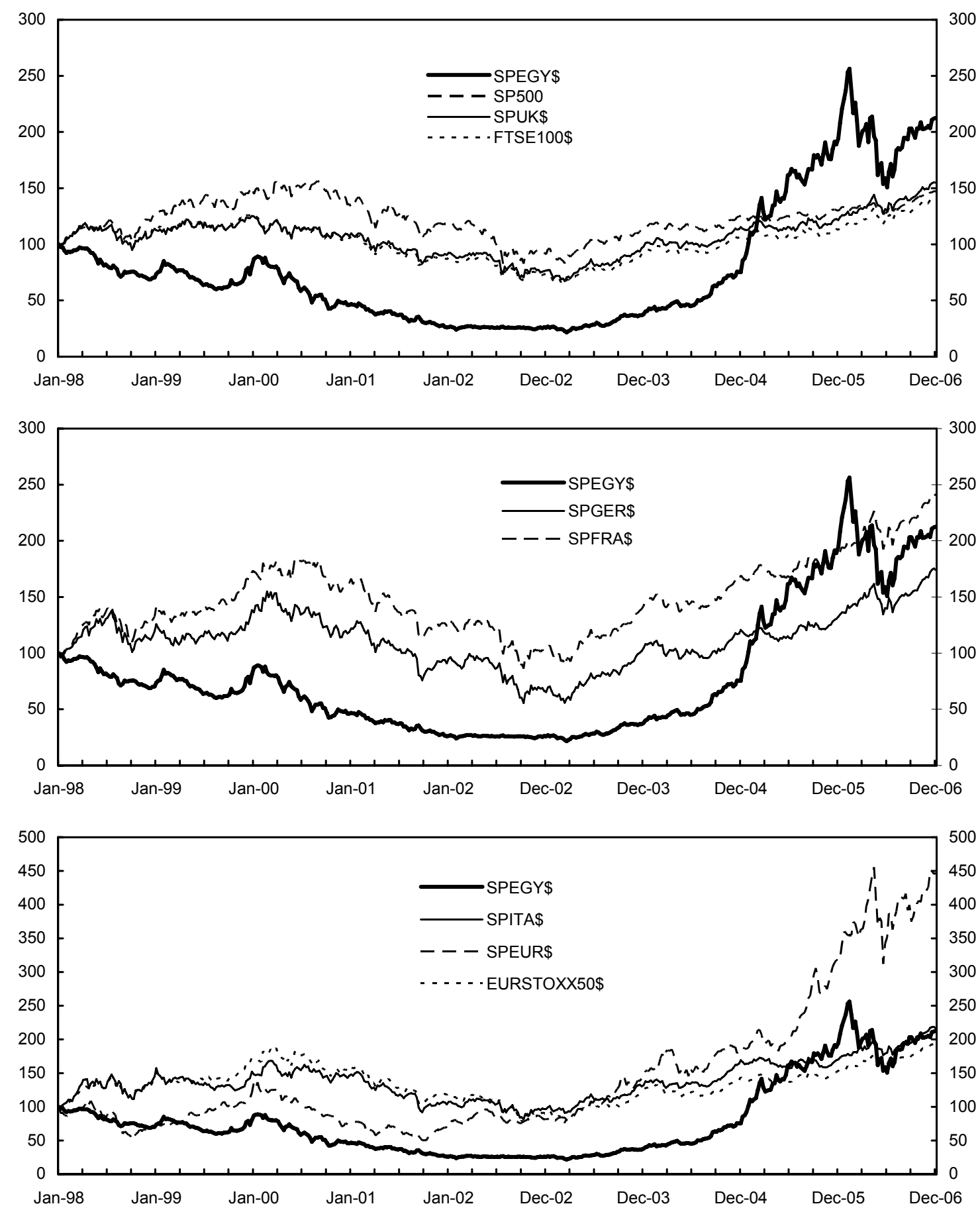

Sources: Datastream; and IMF staff calculations.

Note: See the note to Figure 3. "SP500" stand for the U.S. Standard\&Poors 500 index, "SPUK\$" and "FTSE100\$" are S\&P's British index and the FTSE100, both denominated in U.S. dollar. "SPGER \$", "SPFRA\$", and "SPITA\$" describe Germany's, France's, and Italy's indices in the S\&P database, "SPEUR $\$$ " is an index that includes emerging European markets, and "EUROSTOXX50\$" is the Euopean blue chip index (all in U.S. dollar). 


\section{REFERENCES}

Allen, F., and D. Gale, 2003, "Asset price bubbles and stock market interlinkages" in Asset price bubbles, ed. by W.C. Hunter, G. G. Kaufman, and M. Pomerleano (Cambridge: MIT Press).

Billmeier, A., and I. Massa, 2007, "What Drives Stock Market Development in the Middle East and Central Asia-Institutions, Remittances, or Natural Resources?" forthcoming as IMF Working Paper (Washington: International Monetary Fund).

Blanchard, O., and M. Watson, 1982, "Bubbles, Rational Expectations, and Financial Markets" in Crises in the Economic and Financial Structure, ed. by P. Wachter (Lexington: Lexington Books).

Brooks, C., and A. Katsaris, 2003, "Rational Speculative Bubbles: An Empirical Investigation of the London Stock Exchange," Bulletin of Economic Research, Vol. 55(4), pp. 319-346.

Diba, B. T, and H. I. Grossman, 1988a, "The Theory of rational bubbles in stock prices," The Economic Journal, Vol. 98, pp. 746-754.

—_ 1988b, "Explosive Rational Bubbles in Stock Prices?” American Economic Review, Vol. 78, pp. 520-530.

Gordon, M. J., 1962, The Investment, Financing, and Valuation of the Corporation (Homewood: Richard D. Erwin).

Johansen, S., 1991, "Estimation and Hypothesis Testing of Cointegrating Vectors in Gaussian Vector Autoregressive Models," Econometrica, Vol. 59, pp. 1551-1580.

— 1996, Likelihood-Based Inference in Cointegrated Vector Autoregressive Models, $2^{\text {nd }}$ printing (Oxford: Oxford University Press).

— 2000, "A Bartlett Correction Factor for tests on the cointegrating relations," Econometric Theory, Vol. 16, pp. 740-778.

— , 2002, "A Small Sample Correction Of The Test For Cointegrating Rank In The Vector Autoregressive Model,“ Econometrica, Vol. 70, pp. 1929-1961.

Kindleberger, C., 1992, "Bubbles," in The New Palgrave Dictionary of Money and Finance ed. by P. Newman, M. Milgate, and J. Eatwell (London: Macmillan).

Kleidon, A. W., 1986, "Variance bounds tests and stock price valuation models," Journal of Political Economy, Vol. 94, pp. 953-1001. 
Marsh, T., and R. Merton, 1986, "Dividend Variability and Variance Bounds Tests for the Rationality of Stock Market Prices," American Economic Review, Vol. 76, pp. 483-498.

Organization for Economic Co-operation and Development (OECD), 1998, Economic Outlook No. 64 (Paris: OECD).

Saadi-Sedik, T., and M. Petri, 2006, "The Jordanian Stock Market-Should You Invest in It for Risk Diversification or Performance?” IMF Working Paper No. 06/187 (Washington: International Monetary Fund).

Shiller, R. J., 1981, "Do Stock Prices Move Too Much to Be Justified By Subsequent Changes in Dividends?" American Economic Review, Vol. 71, pp. 421-436.

Tirole, J., 1985, “Asset Bubbles and Overlapping Generations,” Econometrica, Vol. 53, pp. 1499-1528.

Topol, R., 1991, "Bubbles and Volatility of Stock Prices: Effect of Mimetic Contagion," The Economic Journal, Vol. 101, pp. 786-800. 